\title{
Statistical relationship between selected physicochemical properties of peaty-muck soils and their fraction of humic acids**
}

\author{
Patrycja Boguta* and Zofia Sokołowska \\ Institute of Agrophysics, Polish Academy of Sciences, Doświadczalna 4, 20-290 Lublin, Poland
}

Received April 19, 2013; accepted August 12, 2013

\begin{abstract}
A b s t r a c t. Influence of humic acids on soil environment is still subject of scientific discussions. The aim of above studies was to investigate the relationships between selected physicochemical properties of eleven peaty-muck soils and properties of humic acids isolated from these soils. The following parameters were determined for soils: total and organic carbon, density, ash, humification, and the water absorption index. Humic acids were described by: absorbance at $280 \mathrm{~nm}$, absorbance ratios at 465 and $665 \mathrm{~nm}$, at 260 and $665 \mathrm{~nm}$, elemental composition and atomic ratios: H/C, $\mathrm{O} / \mathrm{H}, \mathrm{O} / \mathrm{C}, \mathrm{C} / \mathrm{N}$, the degree of internal oxidation, and the content of carboxylic and phenolic groups. Statistical analyses showed that an increase in density, humification, and water absorption indices of soils caused a significant increase in the humic acid parameters: absorbance at $280 \mathrm{~nm}$, the oxygen content, $\mathrm{O} / \mathrm{H}, \mathrm{O} / \mathrm{C}$ ratios, internal oxidation degree, and functional groups. Statistically significant negative correlations were found for the same parameters of soils and for the hydrogen and carbon content as well as the H/C ratio of humic acids. The relationships showed that there was a possibility to express the properties of humic acids on the basis of more simple parameters measured for soil and without time-consuming isolation of humic acids.
\end{abstract}

K e y w o r d s: organic soils, humic acids, humification

\section{INTRODUCTION}

The peatlands of the Polesie Lubelskie Region as well as those situated in the region of the Biebrza River belong to one of the most valuable natural resources of Poland. Apart from their high touristic values, these areas are also the habitat of unique fauna and flora. Peatlands are also a large reservoir of organic matter that is responsible for sorption properties, structure of soils, and microbial activity. How-

*Corresponding author e-mail: p.warchulska@ipan.lublin.pl **The work was partly financed from the budget of the National Science Centre, Poland, as research project No. DEC 2011/03/ N/NZ9/04239. ever, peats still undergo various continuing transformations related both to natural processes and, in particular, to inappropriate water economy (offhand land reclamation treatments). Most of the peatlands in Poland have been drained and subjected to agricultural use. Processes of such kind cause acceleration of peat mass transformation to mucks (Inisheva and Dement'eva, 1998). Changes in peat evolution under melioration processes are mostly characterized by mineralization and secondary humification. The above processes lead to changes in the morphological, chemical, biological, and physical properties of soils (Klavins et al., 2008; Matyka-Sarzyńska and Sokołowska, 2004; Sokołowska et al., 2011). Consequently, soil mass loses its sorption abilities and gains more hydrophobic character. Mucking processes lead to contracting and decomposition to smaller grain of organic mass. Peat mass stops growing, humidity is also decreased periodically, and oxygen supply increases (Sokołowska and Boguta, 2010). Biological decomposition succeeds and, as a result, the root layer and the upper part of boggy ground of peat transform to muck - organic material with black or brown color. Such mucking peats have recently become interesting for agriculture because they contain very valuable humus substances including humic and fulvic acids. These fractions have a high sorption capacity (Asing et al., 2009) and play a significant role in cation exchange. Humus substances have a physical and physicochemical function of promoting good soil structure (stability of aggregates of soil particles), thereby improving soil fertility (Piccolo, 2002), aeration, retention of moisture, buffering and exchange capacity of soils (Boguta and Sokołowska, 2012; Garcia-Gil et al., 2004; Pertusatti and Prado, 2007). Humic and fulvic acids contribute to plant growth through 
their effect on not only the physical and chemical but also biological properties of the soil. It is mainly a nutritional function, as they serve as a source of N, P, and cations for plant growth (Arancon et al., 2006). These fractions affect the activities of microflora and microfauna organisms by playing a role as an energy source. The above-mentioned facts contribute to the great role of humus substances in controlling the physical and chemical properties of soils, especially organic soils. However, humus substances can differ in terms of humification, oxidation, aromaticity, the content of functional groups, or molecular weight. These differences can affect the influence of humic acids on all soil properties. In consequence, knowledge about chemical and physical properties of humus substances could be helpful in choosing optimal conditions of agricultural cultivations. However, isolation and investigation of humic and fulvic acids are still expensive and time consuming, especially in the agriculture context.

The main objective of these studies was to check if the properties of humic acids could be expressed by some physicochemical properties of soil from which humic acids were isolated. In the case of existence of any statistically significant correlations between the properties of humic acids and soils, it would be possible to assess the state and quality of humic acids on the basis of easier, simpler and not time-consuming measurements of soil.

\section{MATERIALS AND METHODS}

Eleven peaty-muck soils (designed as S1-S11) formed from proper peats were taken from different areas of Polesie Lubelskie and the Biebrza River valley from the depth of 5-10 cm. According to Okruszko classification (Okruszko, 1976), 5 of them represented typical peaty mucks (designed as $Z_{1}$ ) and 6 - proper mucks (designed as $Z_{3}$ ). The studied soil materials were described by selected physicochemical parameters. Secondary transformation was expressed as the water absorption index $\left(\mathrm{W}_{1}\right)$ determined according to the Gawlik method (1992). Humification of samples was described by the Springer humification index $\left(\mathrm{H}_{\mathrm{z}}\right)$ (Schlichting et al., 1995). Total $\left(\mathrm{C}_{\text {tot. }}\right)$ and organic $\left(\mathrm{C}_{\text {org. }}\right)$ carbon was measured using a Carbon/Nitrogen analyzer TOC MULTI N/C 2000, HT 1300 (Analytik Jena). The ash content and bulk density were measured according to Sapek and Sapek (1997).

After the above investigations, humic acids (designed as HA1-HA11) were isolated from soils using alkaline extraction (Swift, 1996). Elemental analysis of nitrogen, carbon, and hydrogen was performed for humic acids using a Perkin - Elmer CHN 2400 analyzer. The oxygen content was calculated from the difference: $100 \%-\mathrm{H} \%-\mathrm{C} \%-\mathrm{N} \%$. Data were presented as weight percentage. From the results obtained, atomic ratios $\mathrm{H} / \mathrm{C}, \mathrm{O} / \mathrm{H}, \mathrm{O} / \mathrm{C}$, and $\mathrm{C} / \mathrm{N}$ were calculated as well as the degree of internal oxidation $(\omega)$, expressed as $\omega=[(2 \mathrm{O}+3 \mathrm{~N})-\mathrm{H}] / \mathrm{C}$. Carboxylic functional groups as well as the total amount of carboxylic and phenolic groups of humic acids were determined using the titration technique according to the Kucharenko and Dragunowa methods (Dziadowiec, 1990). FTIR spectra of humic acids were recorded on the FTIR Thermo Nicolet spectrometer, Nexus (ThermoScientific), after forming pastilles with $\mathrm{KBr}$. Intensity of peaks typical for carboxylic (1 619-1 $\left.639 \mathrm{~cm}^{-1}\right)$ and phenolic (3 389-3 $401 \mathrm{~cm}^{-1}$ ) functional groups of humic acids was measured in absorbance units. Optical ratios E4/E6 and E2/E6 were calculated on the basis of absorbance of humic acid solutions: $40 \mathrm{mg} \mathrm{dm}^{-3}, \mathrm{pH} \mathrm{8}$, at 465, 665, and $260 \mathrm{~nm}$. Kumada parameter $\Delta \log \mathrm{K}$ was calculated from formula $\log \mathrm{A}_{400}-\log \mathrm{A}_{600}$, where 400 and 600 related to absorbance at 400 and $600 \mathrm{~nm}$. All measurements were carried out in three repetitions and averaged. FTIR spectra were averaged using spectrometer software. Normal distribution of all data obtained was verified by the Saphiro-Wilk test. Correlation coefficients were calculated between measured properties of the studied soils and humic acids isolated from them. Statistical evaluation of correlation coefficients was performed using a t-student test with $\alpha=0.05$.

\section{RESULTS AND DISCUSSION}

Selected physicochemical parameters of the studied organic soils are presented in Table 1.

According to Gawlik classification (1992) of the water absorption index $\left(\mathrm{W}_{1}\right)$, class $\mathrm{I}$ of $\mathrm{W}_{1 \in}<0.36-0.45>$ (initial stage of transformation) was represented by sample S8. Class II $\mathrm{W}_{1 \in}<0.46-0.60>$ (weak secondary transformation) was represented by samples: S1, S6, and S7. Samples S2, S3, S5, S9, S10, and S11 exhibited medium secondary transformation with $\mathrm{W}_{1 \in}<0.61-0.75>$, and sample $\mathrm{S} 4\left(\mathrm{~W}_{1}=0.82\right)$ was characterized by strong secondary transformation. The humification index was the highest for samples S4, S3, and $\mathrm{S} 2$ and the lowest for S8, S11, and S1. In the case of the studied samples, the total carbon content changed from 249 to $419 \mathrm{mg} \mathrm{C} \mathrm{g}^{-1}$ dry mass (d.m.). The highest value was found for sample S5 and the smallest one for sample S11. This could be evidence of the lowest and the highest degree of transformation of peat mass into muck, respectively. Such a statement is based on the fact that mucking processes are composed of not only humification but also mineralization, whereas some part of carbon during the mineralization process is released to the atmosphere in the form of carbon dioxide. The content of organic carbon in the soils was only a little lower than the total organic carbon and ranged from 241 (S11) to 393 (S5) $\mathrm{mg} \mathrm{C} \mathrm{g}^{-1} \mathrm{~d}$.m. Higher organic carbon could be evidence of weakly advanced processes of mineralization (Keller et al., 2004). The ash content of the soils ranged from 16.4 to $26.8 \%$. The content of mineral compounds in mucking peats could give information on the advancement of mucking processes and decomposition of peat mass. On the basis of this fact, it could be assumed that mineralization processes had the strongest participation in samples with the highest ash content (soil S1, S6, S7, S8, 
T a b l e 1. Selected physicochemical properties of studied peaty-muck soils. The presented results are an averaged value from three replicates

\begin{tabular}{cccccccc}
\hline No. of soil & Kind of soil & $\mathrm{W}_{\mathbf{1}}$ & $\mathrm{H}_{\mathrm{z}}$ & $\begin{array}{c}\mathrm{C}_{\text {tot. }} \\
\left(\mathrm{mg} \mathrm{g}^{-1} \text { d.m. }\right)\end{array}$ & $\begin{array}{c}\mathrm{C}_{\text {org. }} \\
\left(\mathrm{mg} \mathrm{g}^{-1} \text { d.m. }\right)\end{array}$ & $\begin{array}{c}\mathrm{A} \\
(\% \text { d.m. })\end{array}$ & $\begin{array}{c}\mathrm{d} \\
\left.(\mathrm{g} \mathrm{cm})^{-3}\right)\end{array}$ \\
\hline S1 & $\mathrm{Z} 1$ & 0.55 & 15 & 329.7 & 302.5 & 26.8 & 0.23 \\
S2 & $\mathrm{Z} 3$ & 0.72 & 21 & 312.4 & 301.6 & 20.0 & 0.33 \\
S3 & Z3 & 0.72 & 22 & 337.2 & 323.7 & 21.1 & 0.35 \\
S4 & Z3 & 0.82 & 23 & 338.2 & 334.0 & 25.1 & 0.37 \\
S5 & Z3 & 0.65 & 17 & 419.3 & 392.8 & 21.3 & 0.34 \\
S6 & Z3 & 0.60 & 14 & 292.7 & 272.3 & 25.3 & 0.30 \\
S7 & Z1 & 0.48 & 16 & 379.5 & 342.1 & 26.6 & 0.24 \\
S8 & Z1 & 0.44 & 11 & 371.1 & 336.3 & 25.8 & 0.19 \\
S9 & Z1 & 0.61 & 19 & 407.2 & 380.5 & 16.4 & 0.25 \\
S10 & Z1 & 0.61 & 18 & 335.9 & 311.0 & 19.2 & 0.27 \\
S11 & Z3 & 0.74 & 19 & 249.1 & 241.2 & 25.1 & 0.32 \\
\hline
\end{tabular}

$\mathrm{W}_{1}$ - water absorption index, $\mathrm{H}_{\mathrm{z}}$ - humification index, $\mathrm{A}$ - ash, $\mathrm{d}$ - bulk density, $\mathrm{Z}_{1}$ - peaty muck, $\mathrm{Z}_{3}$ - proper muck. Standard deviations did not exceed $5 \%$.

T a b l e 2. Chemical properties determined for studied humic acids. The presented results are an averaged value from three replicates

\begin{tabular}{|c|c|c|c|c|c|c|c|c|c|c|c|c|c|c|c|}
\hline \multirow{2}{*}{$\begin{array}{l}\text { No. } \\
\text { HA }\end{array}$} & \multirow{2}{*}{ E4/E6 } & \multirow{2}{*}{ E2/E6 } & \multirow{2}{*}{$\Delta \log \mathrm{K}$} & \multirow{2}{*}{$\mathrm{A}_{280}$} & $\mathrm{C}$ & $\mathrm{N}$ & $\mathrm{H}$ & $\mathrm{O}$ & \multirow{2}{*}{$\mathrm{H} / \mathrm{C}$} & \multirow{2}{*}{$\mathrm{O} / \mathrm{H}$} & \multirow{2}{*}{$\mathrm{O} / \mathrm{C}$} & \multirow{2}{*}{$\mathrm{C} / \mathrm{N}$} & \multirow{2}{*}{$\omega$} & \multirow{2}{*}{\multicolumn{2}{|c|}{$\begin{array}{r}\mathrm{COOH} \mathrm{COOH} \\
+\mathrm{OH}\end{array}$}} \\
\hline & & & & & \multicolumn{4}{|c|}{$(\%)$} & & & & & & & \\
\hline HA1 & 4.3 & 31.3 & 0.74 & 1.95 & 46.92 & 3.48 & 4.88 & 44.72 & 1.25 & 0.57 & 0.71 & 15.73 & 0.37 & 420 & 553 \\
\hline HA2 & 3.4 & 26.1 & 0.70 & 2.01 & 46.18 & 3.83 & 4.42 & 45.57 & 1.15 & 0.64 & 0.74 & 14.08 & 0.54 & 401 & 642 \\
\hline HA3 & 3.8 & 26.0 & 0.70 & 2.10 & 46.58 & 3.08 & 4.45 & 45.89 & 1.15 & 0.64 & 0.74 & 17.62 & 0.50 & 416 & 648 \\
\hline HA4 & 4.5 & 38.7 & 0.79 & 1.88 & 46.57 & 3.17 & 4.66 & 45.60 & 1.20 & 0.61 & 0.73 & 17.13 & 0.44 & 409 & 645 \\
\hline HA5 & 5.3 & 64.2 & 0.93 & 1.68 & 48.08 & 3.50 & 5.04 & 43.38 & 1.26 & 0.54 & 0.68 & 16.04 & 0.28 & 359 & 593 \\
\hline HA6 & 5.1 & 47.2 & 0.86 & 1.67 & 47.87 & 3.86 & 4.92 & 43.35 & 1.23 & 0.55 & 0.68 & 14.46 & 0.33 & 360 & 564 \\
\hline HA7 & 5.1 & 60.0 & 0.90 & 1.61 & 48.34 & 3.73 & 5.45 & 42.48 & 1.35 & 0.49 & 0.66 & 15.11 & 0.16 & 317 & 528 \\
\hline HA8 & 5.7 & 60.4 & 0.91 & 1.55 & 47.91 & 3.38 & 5.16 & 43.56 & 1.29 & 0.53 & 0.68 & 16.56 & 0.25 & 306 & 489 \\
\hline HA9 & 5.7 & 49.7 & 0.85 & 1.74 & 48.19 & 3.48 & 5.18 & 43.14 & 1.29 & 0.52 & 0.67 & 16.14 & 0.24 & 362 & 530 \\
\hline HA10 & 5.7 & 47.3 & 0.83 & 1.72 & 47.45 & 3.79 & 5.02 & 43.73 & 1.27 & 0.54 & 0.69 & 14.60 & 0.32 & 367 & 546 \\
\hline HA11 & 5.3 & 46.8 & 0.83 & 1.83 & 47.28 & 3.89 & 4.80 & 44.03 & 1.22 & 0.57 & 0.70 & 14.19 & 0.39 & 422 & 576 \\
\hline
\end{tabular}

HA1-HA11 - number of humic acids, $\omega$ - internal oxidation degree, $\mathrm{A}_{280}$ - absorbance at $280 \mathrm{~nm}, \Delta \operatorname{logK}$ - Kumada humification index. Standard deviations did not exceed $4 \%$.

S11) and the smallest in samples with a low ash content $e g$ $\mathrm{S} 9$. Bulk density ranged widely from 0.19 to $0.37 \mathrm{~g} \mathrm{~cm}^{-3}$. It is a consequence of the diversity of the studied soils in terms of the secondary transformation degree. These two parameters are strongly connected in this kind of soils. The lowest densities $0.19-0.27 \mathrm{~g} \mathrm{~cm}^{-3}$ were found for peaty mucks $\left(Z_{1}\right)$, which simultaneously exhibited a low degree of water absorptivity $\mathrm{W}_{1}(0.44-0.61)$. Higher densities $\left(0.30-0.37 \mathrm{~g} \mathrm{~cm}^{-3}\right)$ were characteristic for proper mucks $\left(Z_{3}\right)$ and these samples had simultaneously higher indices of water absorptivity $\mathrm{W}_{1}(0.6-0.82)$.

Parameters measured for humic acid samples are presented in Table 2.

The studied humic acids exhibited typical values of the E4/E6 parameter for this group of humus compounds. According to Kononowa (1966), they should be below 6 . 
The highest values of E4/E6 (5.3-5.7) were measured for HA8-HA11 and the lowest (3.4 and 3.8) for HA2 and HA3. This index related to the humification degree and it was the lowest for strongly humified humic acids. Simultaneously, it could be claimed that humic acids that exhibited a low value of E4/E6 probably had big molecular mass and a more condensed aromatic structure. High values of E2/E6 were evidence of big participation of weakly humified compounds in the structure, typical for lignins (HAs No. 5, 7, and 8) (Szajdak et al., 2009; Zbytniewski and Buszewski, 2005). The values of $\Delta \operatorname{logK}$ oscillated from 0.7 to 0.93 , which according to Kumada (1987) classified the studied humic acids as medium humified (HA1-HA4) and weakly humified (HA5-HA11). Absorbance values measured at a wavelength of $280 \mathrm{~nm}$ were the highest for HA1-HA3. This might suggest a higher content of aromatic units in the chemical structure of these samples than in samples HA5-HA8, which exhibited the lowest absorbance signals. This could be connected with bigger participation of aliphatic structures than aromatic ones (Uyguner and Bekbolet, 2005). The carbon content in all the studied humic acids was similar and fluctuated from 46.18 (HA2) to $48.34 \%$ (HA7). This percentage content was simultaneously synonymous with the organic carbon concentration. A higher amount of carbon meant a higher degree of humification and this resulted from increasing aromaticity of the structure together with humification progress. Nitrogen varied from 3.08 (HA3) to $3.89 \%$ (HA11) and hydrogen from 4.42 (HA2) to $5.45 \%$ (HA7). The content of oxygen atoms was similar and oscillated from 42.48 (HA7) to $45.89 \%$ (HA3). Atomic ratios H/C (from 1.15 to 1.35 ) calculated according to Van Krevelen (1950) corresponded to aromatic systems coupled with aliphatic chains (below 10 atoms of carbon). HA2 and HA3 possessed the lowest values of the $\mathrm{H} / \mathrm{C}$ ratio, which could be evidence of the high content of aromatic structures as well as strong condensation of these units. An opposite tendency was exhibited by HA7 with the highest $\mathrm{H} / \mathrm{C}$ values (1.35), which indicated a lower content of cyclic structures. The $\mathrm{O} / \mathrm{H}$ ratio changed in the range of 0.49 (HA7) - 0.64 (HA2). The high values of this index evidenced a bigger content of oxygen functional groups like carboxylic, alcoholic, phenolic, enolic, and others, in comparison with other samples with a lower $\mathrm{O} / \mathrm{H}$ ratio. The $\mathrm{O} / \mathrm{C}$ parameter changed from 0.66 (HA7) to 0.74 (HA2). The high values of this index suggested a high degree of oxidation and humification of humic acids. Humic acids with a higher $\mathrm{O} / \mathrm{C}$ value could also have a higher content of carbohydrates. The internal oxidation degree was the lowest for HA7 (0.16) and the biggest for HA2 (0.54). The $\mathrm{C} / \mathrm{N}$ ratios did not differ significantly within the studied part of samples, which demonstrated a similar biological state of the research material (Polak and Sułkowski, 2006). The highest content of carboxylic and phenolic groups was measured for HAs 2, 3, and 4 (642, 648 , and $645 \mathrm{meq} 100 \mathrm{~g}^{-1}$, respectively), whereas the lowest one for HA8 (489 meq $100 \mathrm{~g}^{-1}$ ). The amount of carboxylic groups was about 2 times lower than that of the phenolic functional groups. The highest content of $\mathrm{COOH}$ groups was measured for HA1, 3, and 11 (respectively: 420, 416, and 422 meq $100 \mathrm{~g}^{-1}$ ), whereas the lowest content was found for HA8 (306 meq $100 \mathrm{~g}^{-1}$ ). Analysis of phenolic groups showed the biggest concentration of these structures in HAs 2, 3, 4, and 5 (respectively: 241, 232, 236, 234 meq $100 \mathrm{~g}^{-1}$ ) and the lowest in HA1 (132 meq $\left.100 \mathrm{~g}^{-1}\right)$. The total amount of the groups mentioned above could be evidence of sorption possibilities of the studied humic acids. On the other hand, separate analysis of carboxylic and phenolic functional groups gives information on the acidic nature of the sample. Humic acids with the higher content of carboxylic groups were characterized by a more acidic surface. Phenolic functional groups had a less acidic character. The recorded FTIR spectra of humic acids showed presence of bands typical for this kind of clear compounds. Figure 1 depicts such spectra for selected samples of humic acids (HA 2, 3, 5, and 7).

The spectra show bands coming from stretching vibrations of phenolic and alcohol $\mathrm{OH}$ groups at a wavenumber range from 3401 to $3415 \mathrm{~cm}^{-1}$ (Sakellariadou, 2006). The intensity of bands expressed in absorbance units showed the highest content of $\mathrm{OH}$ groups in HA2 and HA4 and the lowest in HA1 and HA8. Alkanes and cycloalkanes were absorbed in the range of $2850-3000 \mathrm{~cm}^{-1}$ (Pospíśilová et al., 2008; Sakellariadou, 2006). In general, these bands are very strong in humic acids and their location should not change more than $\pm 10 \mathrm{~cm}^{-1}$. The infrared spectra of the studied humic acids had also two bands (maximum at ca. 1716 and $1633 \mathrm{~cm}^{-1}$ ), which could originate from asymmetric stretching vibrations of $\mathrm{COOH}$ and $\mathrm{COO}^{-}$(Bronstein et al., 2007; Pospíšilová et al., 2008). The presence of carboxylic groups was confirmed by bands of symmetric stretching vibrations of the $\mathrm{C}=\mathrm{O}$ structures in the $\mathrm{COOH}$ and $\mathrm{COO}^{-}$groups in wavenumber ranges of $1228-1239$ and $1382-1384 \mathrm{~cm}^{-1}$, respectively. Measurement of the band height indicated the biggest content of $\mathrm{C}=\mathrm{O}$ groups in HA 2 and HA 4 and the smallest in HAs 1,7 , and 8 . However, it should be noted at this point that conclusions about the amount of functional groups on the basis of absorption band height (despite the proportionality of absorbance to the concentration resulting from absorbance laws) could involve a risk of some error resulting from absorption and overlapping of other structure bands.

All the studied parameters both for soils and humic acids tended to exhibit properties of normal distribution, which was confirmed by the Saphiro-Wilk test. In connection with the above, correlation analysis was performed between the determined physicochemical properties of soils and humic acids isolated from them. The results were expressed as correlation coefficients and shown in Table 3. Bold lettering marks statistically significant correlations at $\lambda=0.05$ (t-student test for the significance of the correlation coefficient).

On the basis of the results obtained, it can be seen that the content of total and organic carbon in soils did not show significant relationships with the properties of the studied 


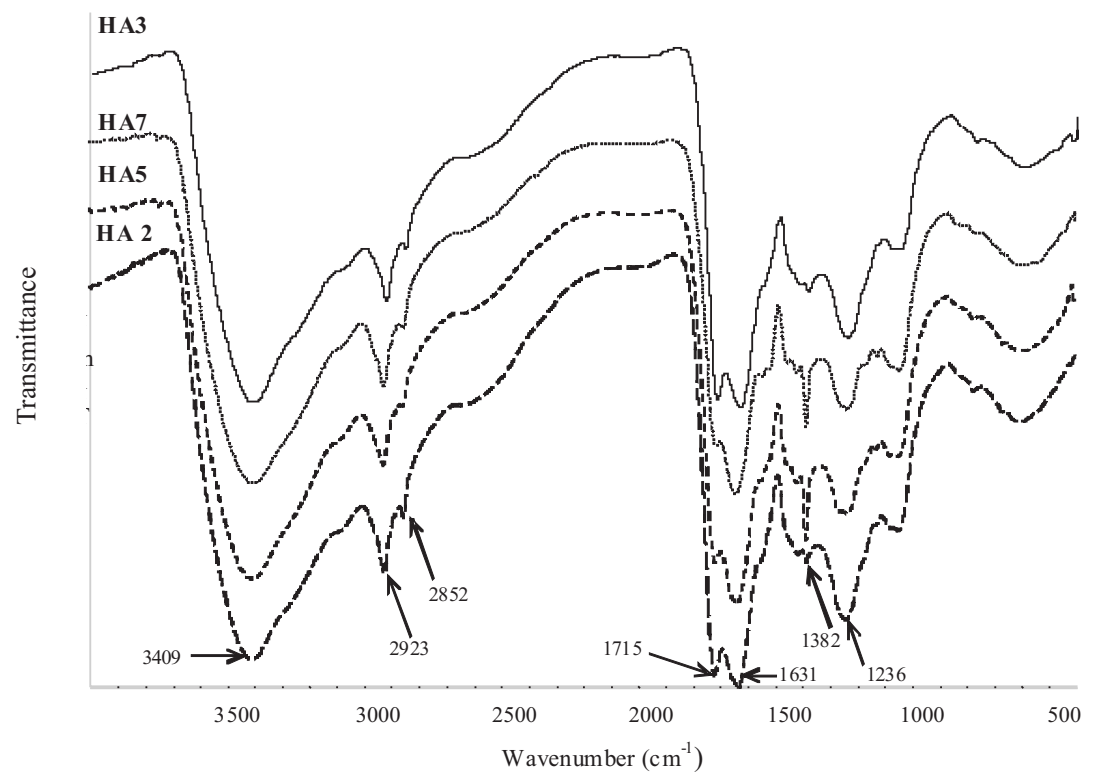

Fig. 1. Infrared spectra of humic acids Nos 2, 3, 5 and 7.

T a b l e 3. Correlation coefficients calculated between selected properties of studied soils and chemical properties of humic acids isolated from peaty-muck soils

\begin{tabular}{|c|c|c|c|c|c|c|}
\hline Property & $\mathrm{W}_{1}$ & $\mathrm{H}_{\mathrm{z}}$ & $\mathrm{C}_{\text {tot. }}$ & $\mathrm{C}_{\text {org. }}$ & A & d \\
\hline E4/E6 & -0.47 & -0.53 & 0.31 & 0.22 & -0.05 & -0.49 \\
\hline E2/E6 & -0.54 & -0.58 & 0.50 & 0.41 & 0.13 & -0.40 \\
\hline$\Delta \log \mathrm{K}$ & -0.53 & -0.60 & 0.46 & 0.37 & 0.16 & -0.38 \\
\hline $\mathrm{A}_{280}$ & 0.66 & 0.72 & -0.38 & -0.27 & -0.19 & 0.56 \\
\hline $\mathrm{C}(\%)$ & -0.67 & -0.63 & 0.52 & 0.40 & 0.03 & -0.54 \\
\hline N (\%) & -0.17 & -0.28 & -0.42 & -0.50 & 0.02 & -0.16 \\
\hline H (\%) & -0.77 & -0.65 & 0.53 & 0.39 & 0.16 & -0.70 \\
\hline $\mathrm{O}(\%)$ & 0.69 & 0.66 & -0.38 & -0.24 & -0.06 & 0.58 \\
\hline $\mathrm{H} / \mathrm{C}$ & -0.77 & -0.63 & 0.52 & 0.38 & 0.18 & -0.73 \\
\hline $\mathrm{O} / \mathrm{H}$ & 0.74 & 0.67 & -0.46 & -0.32 & -0.12 & 0.68 \\
\hline $\mathrm{O} / \mathrm{C}$ & 0.71 & 0.67 & -0.44 & -0.30 & -0.07 & 0.62 \\
\hline $\mathrm{C} / \mathrm{N}$ & 0.08 & 0.19 & 0.50 & 0.56 & -0.02 & 0.10 \\
\hline$\omega$ & 0.76 & 0.65 & -0.56 & -0.43 & -0.14 & 0.67 \\
\hline $\mathrm{COOH}$ & 0.78 & 0.67 & -0.57 & -0.45 & -0.08 & 0.62 \\
\hline $\mathrm{COOH}+\mathrm{OH}$ & 0.88 & 0.83 & -0.29 & -0.12 & -0.18 & 0.92 \\
\hline $\mathrm{OH}_{\text {str. }}$ & 0.80 & 0.74 & -0.13 & 0.03 & -0.25 & 0.85 \\
\hline $\mathrm{COOH}_{\text {asym. }}$ & 0.84 & 0.78 & -0.27 & -0.12 & -0.32 & 0.86 \\
\hline $\mathrm{COO}_{\text {asym. }}^{-}$ & 0.73 & 0.63 & -0.21 & -0.07 & -0.28 & 0.82 \\
\hline
\end{tabular}

$\mathrm{OH}_{\text {str. }}-$ stretching vibrations of $\mathrm{OH}$ group, $\mathrm{COOH}_{\text {asym. }}-$ asymetric vibrations of $\mathrm{COOH}$ group, $\mathrm{COO}_{\text {asym. }}^{-}-$asymetric vibrations of $\mathrm{COO}^{-}$ - group. Bold numbers: significance of R coefficient. Other explanations as in Tables 1 and 2. 
humic acids. Probably, this resulted from the fact that carbon in peaty muck soils could have strongly varied forms and origin. A lot of organic carbon probably came from other humus compounds, for example fulvic acids or humins as well as from different organic compounds in varied stages of decomposition (lignins, fats, carbohydrates, tannins) and plant and animal remains in different stages of transformation. Therefore, the organic carbon in soil could not show a relationship with carbon and other properties of humic acids. Additionally, total carbon also included inorganic parts, mainly carbonates. Very low correlation coefficients were found between the properties of humic acids and the ash content of soils. This can be explained by the fact that ash in peats may originate from different sources, not only from partly transformed peat-forming plants (primary ash), but also from deposition of mineral parts on peats by wind and water (secondary ash), whereas humic acids originate mainly from humification processes of organic matter coming from plant and animal remnants. Therefore, the relationship between the ash content and the properties of humic acids could be weak.

Soil density did not show any significant relationship with the properties of extracted humic acids measured using UV-VIS spectroscopy (E2/E6, E4/E6, $\Delta \operatorname{logK}, \mathrm{A}_{280}$ ) or with the content of oxygen, carbon, and nitrogen of humic acids. Statistically significant negative correlations were found between soil density and the content of hydrogen of humic acids and their $\mathrm{H} / \mathrm{C}$ ratio. An increase in soil density also caused a statistically significant increase in the degree of internal oxidation of humic acids as well as in their atomic ratios $\mathrm{O} / \mathrm{H}, \mathrm{O} / \mathrm{C}$. The density of the studied soils also increased with the increase in the content of carboxylic groups and the cumulative number of carboxylic and phenolic functional groups measured with the Dragunowa and Kucharenko methods; additionally, density increased with FTIR absorbance of $\mathrm{OH}_{\text {str.., }} \mathrm{COOH}_{\text {asym.., }} \mathrm{COO}^{-}$asym. bands. Examples of the relationships between parameters of humic acids and density of soils are presented in Figs 2 and 3 (correlation with the height of absorption bands of functional groups and correlation with atomic ratios and the internal oxidation degree, respectively).

The correlation coefficients of the above relationships were high and statistically significant. The close connection between soil density and the above-mentioned properties of the isolated humic acids was very interesting and was probably due to the great degree of progressing mucking processes, which had an influence on both soil density and the physical, chemical, and physicochemical properties of organic substances, mainly their colloidal part including humic acids. The increase in peat density and thus the decrease in their porosity during mucking processes could be explained by progressing processes of dehydration. On the other hand, this is connected with emergence of circumstances favourable for humification of organic compounds

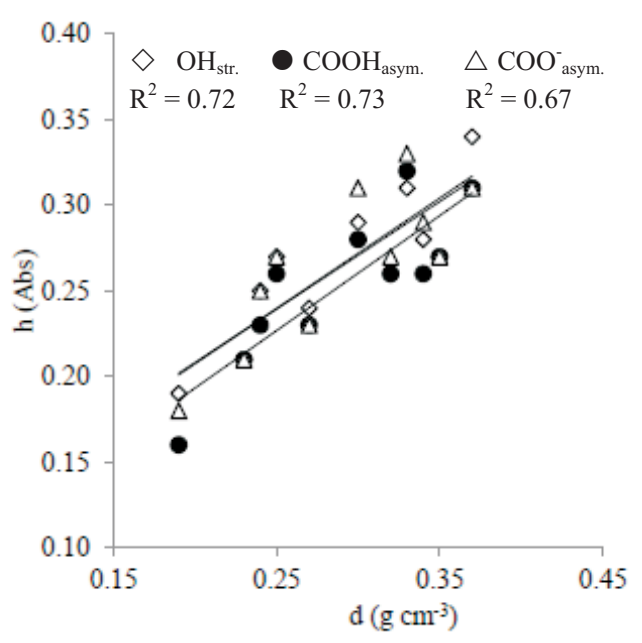

Fig. 2. Relationship between the density of peaty-muck soils and the functional groups of isolated humic acids measured as absorbance of FTIR bands.

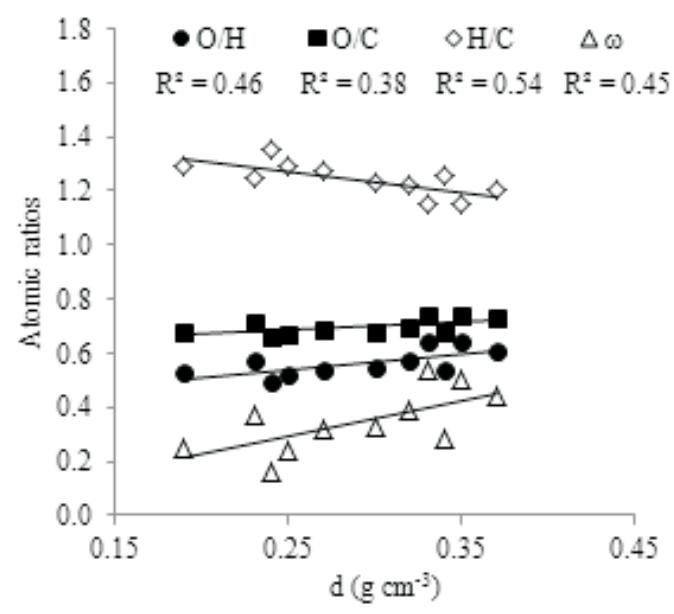

Fig. 3. Relationship between the density of peaty-muck soils and atomic ratios as well as the internal oxidation degree $(\omega)$ of isolated humic acids.

contained in peat, ie cellulose and lignins, into humus substances. Facilitated access to oxygen favours an increase in oxidation of the structure of forming humus substances and an increase in the amount of oxygen functional groups like $\mathrm{COOH}$ and $\mathrm{OH}$, thereby promoting an increase in the exchangeable capacity of all soils (Matyka-Sarzyńska and Sokołowska, 2004). Therefore, parameters of humic acids indicating the oxygen content, eg $\mathrm{O} \%, \mathrm{O} / \mathrm{H}, \mathrm{O} / \mathrm{C}, \omega$, content of $\mathrm{COOH}$ and $\mathrm{OH}$, could positively correlate with changes 
in the density of the studied soils (the correlation with $\mathrm{O} \%$ was positive but the correlation coefficient did not exceed the limit of statistical significance and this should be studied for a greater number of samples). These conclusions are indirectly in agreement with the study of Sokołowska and Matyka-Sarzyńska (2004). Their investigations showed that with progressive mucking, and hence also with humification and mineralisation progress, more new organic compounds were formed and the new substances were characterized by a strongly developed surface, strongly crumbled particles, and density increasing with progression of mucking. Simultaneously, these processes take place at higher access to oxygen; therefore, the structures of progressively forming humic acids are richer in oxygen functional groups.

The humification index and the water absorption index correlated with a majority of humic acid properties and showed statistically significant correlation coefficients with similar R-values for $\mathrm{H}_{\mathrm{z}}$ and $\mathrm{W}_{1}$ and the same direction.

The exception was the lack of a relationship between humification and water absorption indices and the following humic acids parameters: E2/E6, E4/E6, $\Delta \operatorname{logK}, \mathrm{N} \%$, and C/N. These properties of humic acids did not show correlations with density, ash, and the total and organic carbon content of soils either. Absorbance of humic acids measured at $280 \mathrm{~nm}$ increased statistically significantly with the increase in $\mathrm{H}_{\mathrm{Z}}$ and $\mathrm{W}_{1}$ of peaty-muck soils. The increasing absorbance in this area could be connected with the increase in the aromaticity degree of the structures in humic acid particles (Chin et al., 1994). According to Flaig humification theory (Tan, 2000), there is a possibility of an increase in aromatic compounds with the progress of humification. This could explain the positive correlations between soil parameters $\mathrm{W}_{1}$ and $\mathrm{H}_{\mathrm{Z}}$ and the absorbance of humic acids at wavelength $280 \mathrm{~nm}$. Our studies also demonstrated that the increase in soil parameters $\mathrm{H}_{\mathrm{z}}$ and $\mathrm{W}_{1}$ was accompanied by an increase in the internal oxidation degree and oxygen content as well as a decrease in the hydrogen content in the structure of the investigated humic acids. Probably, this was connected with the progress of structure aromatization with a simultaneous decrease in the hydrogen content caused by substitution of hydrogen atoms in aromatic rings by the side chains rich in different functional groups. Moreover, this conclusion was in agreement with the high positive correlation between $\mathrm{H}_{\mathrm{z}}$ and $\mathrm{W}_{1}$ and the content of oxygen functional groups of humic acids $\mathrm{COOH}$ and $\mathrm{OH}$ measured with the Dragunowa and Kucharenko methods. This is shown in Figs 4 and 5 (for the water absorption index and for the humification index, respectively).

Figure 6 shows a correlation between the water absorption index and the calculated atomic ratios of humic acids. It could be seen that the parameters of humic acids that indicate the oxidation and oxygen content $(\mathrm{O} / \mathrm{H}, \mathrm{O} / \mathrm{C}$ and $\omega)$ increased with the increase in the water absorption index, contrary to the $\mathrm{H} / \mathrm{C}$ ratio of the humic acids. Similar direc-

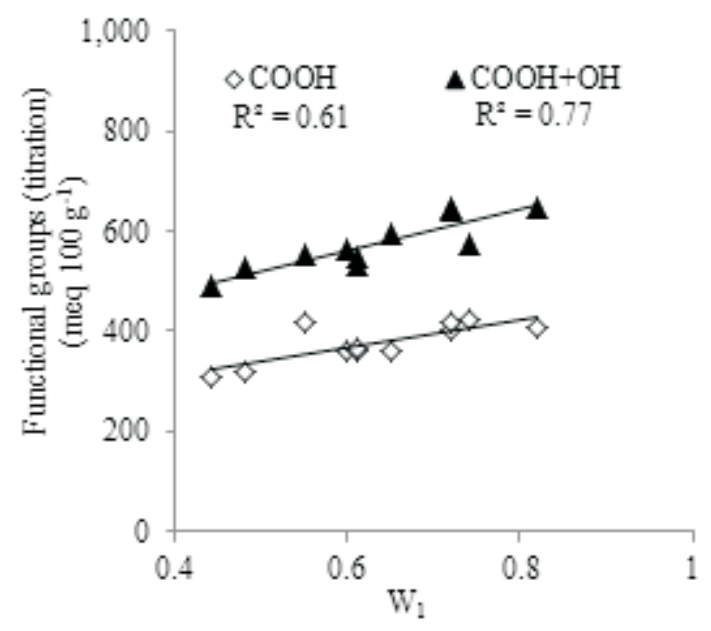

Fig. 4. Relationship between the water absorption index of peatymuck soils and the functional groups (potentiometric titration) of isolated humic acids.

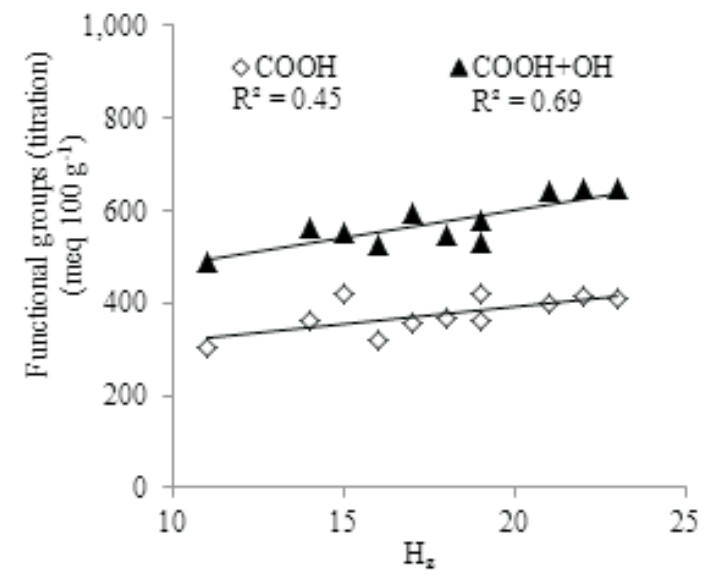

Fig. 5. Relationship between the humification index of peaty-muck soils and the functional groups (potentiometric titration) of isolated humic acids.

tions of statistical relationships were found between the atomic ratios of the humic acids and the humification index of soils. These correlations were also statistically significant and $R$ values equaled $-0.63(\mathrm{H} / \mathrm{C}), 0.67(\mathrm{O} / \mathrm{H}), 0.67(\mathrm{O} / \mathrm{C})$, and $0.65(\omega)$. The increase in the humification and water absorption indices with the oxygen functional groups of the humic acids was also confirmed by high positive correlation coefficients between soil parameters $\mathrm{H}_{\mathrm{z}}, \mathrm{W}_{1}$ and the height of the absorption bands of the $\mathrm{OH}$ and $\mathrm{COOH}$ groups measured on the FRIT spectra of the extracted humic acids. Examples of correlations between the water absorption index of peaty-muck soils and functional groups of the isolated humic acids measured as absorbance of FTIR bands are presented in Fig. 7. The relationships between the height of the absorption bands of $\mathrm{OH}$ and $\mathrm{COOH}$ groups of humic acids and the humification index of soils were also statistically 
significant and had the same positive direction as the correlations with the water absorption index ( $\mathrm{R}$ values equaled 0.74 $\left(\mathrm{OH}_{\text {str. }}\right), 0.78\left(\mathrm{COOH}_{\text {asym. }}\right)$, and $0.63\left(\mathrm{COO}^{-}\right.$asym. $\left.)\right)$.

All these relationships are connected with the fact that during the humification processes, some organic substances (cellulose, lignins, bitumins) are transformed to humus substances: first to fulvic and then to humic acids, and these new substances are enriched in oxygen functional groups. In connection with the above, the amount of carboxylic and phenolic groups can increase, the $\mathrm{O} / \mathrm{C}$ ratio increases too, and consequently oxidation of all the structure occurs. These progressing changes could be expressed for all peat mass by an increasing humification index or by an increasing water absorption index, which is also commonly understood as a secondary transformation index (Szajdak et al., 2012). Probably, this is the cause of the observed relationships between soils parameters $\mathrm{H}_{\mathrm{Z}}, \mathrm{W}_{1}$ and the selected properties of humic acids. The above conclusions are in indirect agreement with other results of Matyka-Sarzyńska and Sokołowska (2004). Their investigations indicated presence of a positive correlation between the surface charge of organic soils and the humification index as well as between the surface charge and the water absorption index. Taking into account the fact that the main source of surface charge in organic soils is the oxygen functional groups of humus substances, one could assume that some relationship is highly possible between $\mathrm{W}_{1}, \mathrm{H}_{\mathrm{z}}$ of soil and the functional carboxylic or phenolic groups of humic acids. Therefore, these results could be compared to our studies although the conclusions concern the correlations between soil properties and the properties of humic acids.

In summary, we would like to stress that in this paper we made an attempt at finding connections between the properties of humic acids and those of whole soils. Using simple statistical tests, we tried to find out whether the above dependences were significant and what the strength of the relationships was. The present results confirmed the presence of statistically significant relationships between selected physicochemical properties of organic soils and some chemical properties of humic acids isolated from these soils. The discussion showed that all significant relationships resulted from changes that took place during the mucking processes, especially from the progressing humification processes. The high correlation indices between the parameters of soils and humic acids of these soils could be evidence of the importance of the humic acid fraction in processes of organic soil transformation like humification and mineralization. Simultaneously, the results obtained showed that the state and properties of humic acids could be described by simpler parameters measured only for soil and without time-consuming isolation of the humic acid fraction. This was possible when the mathematical function between humic acids and soil properties was known and

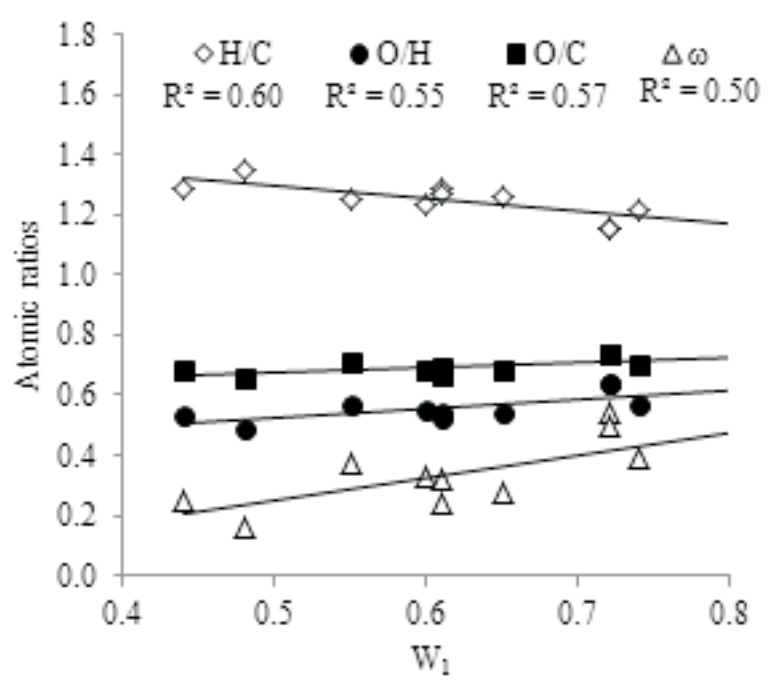

Fig. 6. Relationship between the water absorption index of peatymuck soils and atomic ratios as well as the internal oxidation degree $(\omega)$ of isolated humic acids.

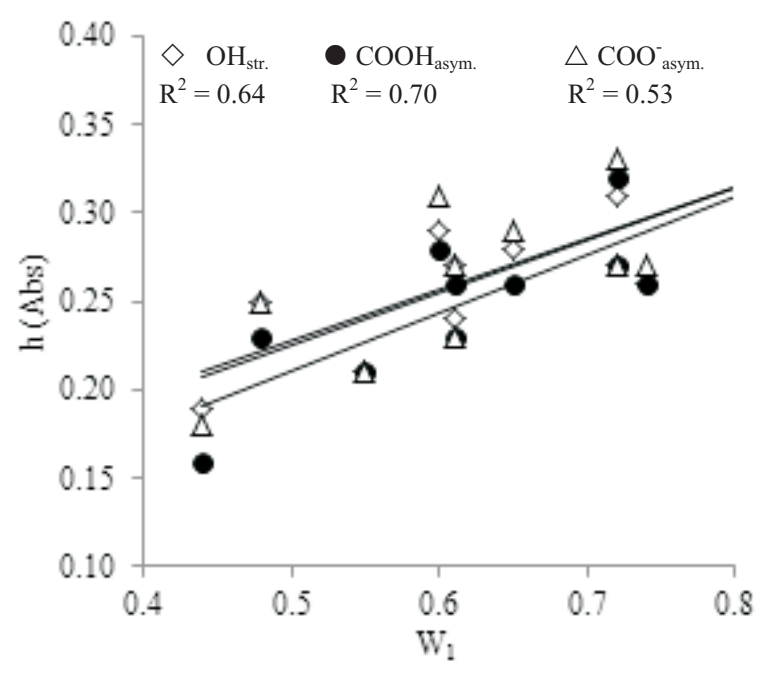

Fig. 7. Relationship between the water absorption index of peatymuck soils and the functional groups of isolated humic acids measured as absorbance of FTIR bands.

when the relationships were statistically significant. Knowledge about presence of a statistical function between the properties of humic acids and whole soil could be highly valuable for ecology in terms of organic soil protection and for agriculture where simple information about soil would describe one of the most important soil components ie humic acids. 


\section{CONCLUSIONS}

1. Increasing soil density resulted in an increase: atomic ratios $\mathrm{O} / \mathrm{H}, \mathrm{O} / \mathrm{C}$, internal oxidation degree, and the content of carboxylic and phenolic functional groups of humic acids. The positive correlations could be explained by the progressing mucking process resulting in dehydration, crumbling and, consequently, a decrease in porosity and an increase in the density of soil mass. Simultaneously, progress of mucking processes is connected with progress of humification and takes place in strongly aerobic circumstances, which is related to formation of humic acids rich in oxygen functional groups like carboxylic, alcoholic, and phenolic groups.

2. The increase in the humification index and the water absorption index of the studied soils was accompanied by an increase in the humic acid parameters such as the content of oxygen and oxygen functional group, atomic ratios $\mathrm{O} / \mathrm{H}$, $\mathrm{O} / \mathrm{C}$, internal oxidation degree, and aromaticity of humic acids measured as absorbance at $280 \mathrm{~nm}$. The high correlation coefficients between the above-mentioned parameters allow an assumption that humic acids constituted a great part of humus substances in the studied soils and, consequently, this fraction played a dominant role in determination of the properties of the entire soil system.

3. Ash and total and organic carbon of the studied soils did not have a significant influence on the measured chemical properties of humic acids. This may have resulted from the presence of other forms of carbon in soils, for example inorganic or even organic carbon but not extractable by alkaline solutions.

4. The results obtained show that there is a possibility to evaluate the state, quality, and properties of humic acids on the basis of more simple parameters measured only for soil and without time-consuming isolation of the humic acid fraction. Knowledge about the presence of a statistical function between the properties of humic acids and whole soil could be highly valuable for ecology in terms of organic soil protection and for agriculture where simple information about soil would describe one of the most important soil components ie humic acids.

\section{REFERENCES}

Arancon N.Q., Edwards C.A., Lee S., and Byrne R., 2006. Effects of humic acids from vermicomposts on plant growth. European J. Soil Biol., 42, 65-69.

Asing J., Wong N.C., and Lau S., 2009. Optimization of extraction method and characterization of humic acid derived from coals and composts. J. Trop. Agric. and Fd. Sc., 37(2), 211-223.

Boguta P. and Sokołowska Z., 2012. Influence of phosphate ions on buffer capacity of soil humic acids. Int. Agrophys., $26,7-14$.
Bronstein L.M., Huang X., Retrum J., Schmucker A., Pink M., Stein B.D., and Dragnea B., 2007. Influence of iron oleate complex structure on iron oxide nanoparticle formation. Chem. Mater., 19, 3624-3632.

Chin Y.P., Aiken G., and O'Loughlin E., 1994. Molecular weight, polydispersity, and spectroscopic properties of aquatic humic substances. Environ. Sci. Technol., 28, 1853-1858.

Dziadowiec H., 1990. Determination of functional groups in humic acids by Dragunowa and Kucharenko methods. In: Methodical Guide for Studies of Soil Organic Matter (in Polish). Scientific Commission of Polish Soil Society Press, Warsaw, Poland.

Garcia-Gil J.C., Ceppi S.B., Velasco M.I., Polo A., and Senesi N., 2004. Long-term effects of amendment with municipal solid waste compost on the elemental and acidic functional group composition and $\mathrm{pH}$-buffer capacity of soil humic acids. Geoderma, 121, 135-142.

Gawlik J., 1992. Water holding capacity of peat formations as an index of the state of their secondary transformation. Polish J. Soil Sci., 2, 121-126.

Inisheva L.I. and Dement'eva T.V., 1998. Mineralization rate of organic matter in peats. Eurasian Soil Sci., 33(2), 170-176.

Keller J.K., White J.R., Bridgham S.D., and Pastor J., 2004. Climate change effects on carbon and nitrogen mineralization in peatlands through changes in soil quality. Global Change Biol., 10, 1053-1064.

Klavins M., Sire J., Purmalis O., and Melecis V., 2008. Approaches to estimating humification indicators for peat. Mires Peat, 3(7), 1-7, http://www.mires-and-peat.net/volumes/ map03/ map0307.php

Kononowa M.M., 1966. Soil Organic Matter: its nature, its role in soil formation and in soil fertility. Pergamon Press, Oxford, UK.

Kumada K., 1987. Chemistry of soil organic matter. Japan Scientific Soci. Press, Tokyo, Japan.

Matyka-Sarzyńska D. and Sokołowska Z., 2004. Usefulness of humification number in studies of the state of secondary transformation as comparison to water holding capacity of mucks. Acta Agrophysica, 106, 553-563.

Okruszko H.,1976. Discernment and division of hydrogenic soils in relations to reclamation necessity (in Polish). Bibl. Wiad. IMUZ, 52, 7-54.

Pertusatti J. and Prado A.G.S., 2007. Buffer capacity of humic acid: Thermodynamic approach. J. Colloid Interface Sci., 314, 484-489.

Piccolo A., 2002. The supramolecular structure of humic substances. A novel understanding of humus chemistry and application in soil science. Advances Agronomy, 75, 57-133.

Polak J. and Sułkowski W.W., 2006. Influence of the Treatment Process on Nitrogen Content in Humic Acids Extracted from Sewage Sludge. Polish J. Environ. Stud., 15(4), 573-577.

Pospíšilová L., Fasurová N., Barančíková G., and Liptaj T., 2008. Spectral characteristics of humic acids isolated from South Moravian lignite and soils. Petroleum Coal, 50(2), 30-36.

Sakellariadou F., 2006. Spectroscopic studies of humic acids from subsurface sediment samples collected across the Aegean Sea. Mediterranean Marine Sci., 7(2), 11-17. 
Sapek A. and Sapek B., 1997. Methods of chemical analyses of organic soils. Instruction materials, 115, 10.

Schlichting E., Blume H.P., and Stahr K., 1995. Bodenkundliches Praktikum, Blackwell Wissenschafts Press, BerlinWien.

Sokołowska Z. and Boguta P., 2010. State of the dissolved organic matter in the presence of phosphates. In: Chemical, Physical and Biological Processes Occurring in Soils (Eds L.W. Szajdak, A.K. Karabanov). Prodruk Press, Poznań, Poland.

Sokołowska Z., Szajdak L., and Boguta P., 2011. Effect of phosphates on dissolved organic matter release from peatmuck soils. Int. Agrophys., 25, 173-180.

Swift R.S., 1996. Organic matter characterization. In: Methods of Soil Analysis, Chemical Methods (Eds D.L. Sparks, A.L. Page, P.A. Helmke, R.H. Loeppert, P.N. Soltanpour, M.A. Tabatabai, M.E. Sumner). Soil Sci. Soc. Am. Press, Madison, WI, USA.
Szajdak L., Sokołowska Z., and Boguta P., 2012. Kinetics of dissolved organic matter released from peat-moorsh soils of various degree of secondary transformation. Necessity Peatlands Protection, 353-366.

Szajdak L., Warchulska P., and Sokołowska Z., 2009. Effect of $\mathrm{pH}$ on the release of organic matter from mucks. Wiestnik Tomsk State Pedagogical University Bulletin, 3(81), 105-109.

Tan H.K., 2000. Environmental Soil Science. CRC Press, Dekker Press, New York, USA.

Uyguner S.C. and Bekbolet M., 2005. Evaluation of humic acid photocatalytic degradation by UV-VIS and fluorescence spectroscopy. Catalysis Today, 101, 267-274.

Van Krevelen D.W., 1950. Graphical-statistical method for investigation of the structure of coal. Fuel, 26, 269-284.

Zbytniewski R. and Buszewski B., 2005. Characterization of natural organic matter (NOM) derived from sewage sludge compost. Part 1: chemical and spectroscopic properties. Bioresource Technol., 96, 471-478. 